\title{
The genome of Diuraphis noxia, a global aphid pest of small grains
}

\author{
Scott J Nicholson 1,3, Michael L Nickerson², Michael Dean², Yan Song ${ }^{3}$, Peter R Hoyt ${ }^{3}$, Hwanseok Rhee ${ }^{4}$, \\ Changhoon $\mathrm{Kim}^{4}$ and Gary J Puterka ${ }^{1 *}$
}

\begin{abstract}
Background: The Russian wheat aphid, Diuraphis noxia Kurdjumov, is one of the most important pests of small grains throughout the temperate regions of the world. This phytotoxic aphid causes severe systemic damage symptoms in wheat, barley, and other small grains as a direct result of the salivary proteins it injects into the plant while feeding.

Results: We sequenced and de novo assembled the genome of D. noxia Biotype 2, the strain most virulent to resistance genes in wheat. The assembled genomic scaffolds span $393 \mathrm{MB}$, equivalent to $93 \%$ of its $421 \mathrm{MB}$ genome, and contains 19,097 genes. D. noxia has the most AT-rich insect genome sequenced to date (70.9\%), with a bimodal $\mathrm{CpG}_{(\mathrm{O} / \mathrm{E})}$ distribution and a complete set of methylation related genes. The $\mathrm{D}$. noxia genome displays a widespread, extensive reduction in the number of genes per ortholog group, including defensive, detoxification, chemosensory, and sugar transporter groups in comparison to the Acyrthosiphon pisum genome, including a $65 \%$ reduction in chemoreceptor genes. Thirty of 34 known $D$. noxia salivary genes were found in this assembly. These genes exhibited less homology with those salivary genes commonly expressed in insect saliva, such as glucose dehydrogenase and trehalase, yet greater conservation among genes that are expressed in D. noxia saliva but not detected in the saliva of other insects. Genes involved in insecticide activity and endosymbiont-derived genes were also found, as well as genes involved in virus transmission, although D. noxia is not a viral vector.
\end{abstract}

Conclusions: This genome is the second sequenced aphid genome, and the first of a phytotoxic insect. D. noxia's reduced gene content of may reflect the influence of phytotoxic feeding in shaping the D. noxia genome, and in turn in broadening its host range. The presence of methylation-related genes, including cytosine methylation, is consistent with other parthenogenetic and polyphenic insects. The D. noxia genome will provide an important contrast to the A. pisum genome and advance functional and comparative genomics of insects and other organisms.

Keywords: Diuraphis noxia, Russian wheat aphid, Plant-insect interactions, Phytotoxic, Aphid, Genome

\section{Background}

Aphids rapidly radiated as parasites of flowering plants following the spread and diversification of angiosperms 80 to 150 million years ago [1,2]. From that point forward, aphids developed host-specific relationships through use of specialized piercing-sucking mouth parts that penetrate plant tissues to feed upon phloem sap. Key to this feeding process is the injection of saliva which modulates plant defenses $[3,4]$. More than 5,000 aphid species exist, and over 100 species are economically important crop

\footnotetext{
* Correspondence: gary.puterka@ars.usda.gov

'USDA Agricultural Research Service, Stillwater, OK 74075, USA

Full list of author information is available at the end of the article
}

pests [5]. The Russian wheat aphid, Diuraphis noxia Kurdjumov, gained recognition as a global pest of wheat when it rapidly expanded its range from Central Asia and Europe [6] to most of the wheat producing continents over a 15 year period beginning in the early 1970s [7,8]. Losses in wheat exceeded $\$ 986$ million over the first 10 years after this aphid invaded the United States in 1986 [9].

The genome of the pea aphid, Acyrthosiphon pisum, is currently the sole genomic model available for study of aphid biology, genetics, and aphid-plant interactions [10]. A. pisum and D. noxia share many biological traits common to the family Aphididae. However, a phylogenetic analysis of Buchnera aphidicola sequences from a 
large sample of aphid species indicated that $D$. noxia diverged early in the evolution of the tribe Macrosiphini in the subfamily Aphidinae [11], which includes A. pisum, to develop unique host preferences and feeding relationships. The majority of aphids, including A. pisum, cause minor damage to their host plants by imposing a metabolic burden through constant removal of phloem sap $[3,4,12,13]$. In contrast, $D$. noxia represents an economically important group of aphids whose saliva induces rapid, direct, and systemic phytotoxic effects in the host plant, including chlorosis, loss of turgor, abnormal leaf growth, and necrosis [3,14]. A pisum is a well known vector of plant viruses [15] and expanded its host range in legumes through the development of host races that are specific to a plant species $[16,17]$. D. noxia is not a vector of plant viruses [18], and feeds upon over 140 species in 40 genera of graminaceous plants including wheat and barley [19]. This species demonstrates the ability to develop virulent strains, termed biotypes, in response to single gene-based resistance in wheat [20-22] which follows a virulence gene-resistance gene model often associated with plant-parasite relationships [23-25]. Currently, no additional $D$. noxia-resistant wheat cultivars have been released since 2003, when D. noxia Biotype 2 overcame $D n 4$ gene-based resistance in wheat. Although $D$. noxia is generally known to reproduce sexually, Biotype 2 is strictly parthenogenetic and a highly successful isofemale component of the genotypically diverse population in the United States [24].

We present this draft version of the $D$. noxia genome as the first crucial step in the study of phytotoxic aphidplant interactions and the virulence genes that overcome resistance genes in wheat. The advancement of a phytotoxic aphid model will increase the understanding of how virulence genes and their products neutralize host plant resistance genes and the underlying mechanisms of the different aphid-host interactions. Further, the $D$. noxia genome provides an exceptional contrast to $A$. pisum that will facilitate functional and comparative genomics studies of aphids and advance the science of how insects adapted to perform their specialized roles in the environment.

\section{Results and discussion \\ Genome assembly}

Genomic DNA from a parthenogenetic isofemale line of $D$. noxia Biotype 2 was sequenced using an Illumina Hi-Seq 2000 and quality filtered, resulting in 496,145,410 paired end reads (read length $101 \mathrm{bp}$, fragment length $223 \mathrm{bp}), 475,489,616$ individual $2.5 \mathrm{~kb}$ mated-pair reads and two independent $8 \mathrm{~kb}$ mated pair libraries with $369,474,230$ individual reads that were used for de-novo assembly by Allpaths-LG (Table 1). Final genome coverage was 104X, and the assembly consisted of 49,379 contigs ( $>1,000 \mathrm{bp}, \mathrm{N}_{50}=12,578$ bases $)$ and 5,641 scaffolds $\left(\mathrm{N}_{50}=397,774\right.$ bases) (Table 2). The genomic scaffolds covered 393,024,634 bases, including 98,530,005 Ns representing unsequenced gaps. RNAseq analysis (Illumina Hi-Seq 2000) was performed using wholebody RNA extracted from the same colony and de novo assembled (Trinity), resulting in 85,990 assembled contigs ( $\geq 200 \mathrm{bp}, \mathrm{N}_{50}=2,863 \mathrm{bp}$ ) (Table 2 ). The D. noxia genome consists of five holocentric chromosomes totaling $421 \mathrm{MB}(1 \mathrm{C})[26,27]$ of which our assembly spans 93\% (393 MB) including gaps. The D. noxia genome as measured by flow cytometry is $18.6 \%$ smaller than the genome of the model aphid A. pisum (517 MB).

The D. noxia genome is composed of $29.1 \% \mathrm{G}+\mathrm{C}$ and $70.9 \% \mathrm{~A}+\mathrm{T}$ which is the lowest $\mathrm{G}+\mathrm{C}$ percentage of any currently-assembled insect genome including $A$. pisum $(29.6 \% \mathrm{G}+\mathrm{C})$ [10]. The median $\mathrm{G}+\mathrm{C}$ composition of all identified D. noxia transcripts, discussed below, is $39.3 \%$ with a range of $21.4 \%$ to $72.0 \%$, compared with medians of $38.8 \%$ in A pisum [10] and $38.6 \%$ in Apis mellifera [28]. The high $\mathrm{A}+\mathrm{T}$ compositions of $D$. noxia and $A$. pisum contradict the hypothesized positive correlation between insect genome size and A + T content [29].

The rate of single nucleotide polymorphisms within the $D$. noxia assembly was measured at $0.45 \%$, and is most likely attributable to the heterozygous chromosomal state that is perpetuated by the strict parthenogenetic reproduction observed in D. noxia Biotype 2 [24]. The experimental population consisted of the offspring of one female aphid, therefore, chromosomal heterozygosity was preserved in this clonal population. $D$. noxia's SNP rate is similar to that of other insects $[30,31]$, is beneath the $\leq 1 \%$ threshold of typical allelic variance [10], and confirms the existence of chromosomal heterozygosity in Biotype 2 , as has been noted in other invasive clonal aphid lineages [32].

The telomeric sequence $\left(\mathrm{TTAGG}_{\mathrm{N}}\right)$ common to insects $[10,33,34]$ was not found in $D$. noxia, supporting the findings of Novotna et al. [27], who were unable to detect common telomere sequences in this aphid by fluorescence in-situ hybridization (FISH) analysis. However, RNAseq read mapping revealed the expression of six telomere-related proteins present in the $D$. noxia genome (Additional file 1: Table S1), suggesting the existence of modified telomeric repeat sequences. The lack of classical telomeric sequences is not surprising as altered telomeric sequences, or the substitution of retrotransposons and satellite repeats, have been reported in several other unrelated insect species [33-36].

The completeness of the $D$. noxia genome was assessed using a hidden Markov model (HMM)-based search (CEGMA) of the genome scaffolds and assembled transcripts to identify individual members of the Conserved Eukaryotic Gene (CEG, $n=248)$ set, which are expected 
Table 1 Quality-filtered and Buchnera-filtered sequencing data used to assemble the $D$. noxia biotype 2 genome

\begin{tabular}{lllll}
\hline Sample Name & Number of reads $\mathbf{( x \mathbf { 1 0 } ^ { \mathbf { 6 } } )}$ & Read Length (BP) & Fragment length (BP) & Total coverage (GBP) \\
\hline Paired-End & 496.1 & $2 \times 101$ & 223 & 50.12 \\
Mated-Pair $\mathbf{2 . 5}$ kb & 475.5 & $2 \times 101$ & 2603 & 48.05 \\
RWA MP 8 kb & 369.5 & $2 \times 101$ & 8898 & 37.33 \\
RWA RNA-seq & 251.8 & $2 \times 101$ & 172 & 42.92 \\
\hline
\end{tabular}

Reads were filtered prior to assembly so that for a pair of PE reads, each read should have $90 \%$ of bases with base quality better than or equal to $\mathrm{Q}_{20}$.

to be present in all eukaryotes [37]. CEGMA analysis determined that the $D$. noxia genome assembly contains 94.4\% of the total CEG set, including 214 complete and 20 partial CEGS, for a total of 234 identified CEGS. CEGMA analysis of the predicted $D$. noxia transcriptome found 247 complete CEGs, or $99.6 \%$ of the CEG set (Table 2). The identification of $94 \%$ of CEGs strongly supports our estimated genome assembly of $93 \%$ with gaps likely due to repetitive regions that are recalcitrant to assembly [31].

\section{CpG dinucleotides and cytosine methylation}

Cytosine methylation is the definitive mark of epigenetic regulation in eukaryotes, but occurs only in the $\mathrm{CpG}$ context in insects [38]. While DNA methylation is present in most insects, it is only rarely observed among the holometabolous insect orders Coleoptera and Diptera, and is suspected to be undergoing evolutionary deletion in these orders $[39,40]$. Among hemipteran insects, A. pisum and Pediculus humanus each display evidence of cytosine methylation, but $P$. humanus lacks the de novo methyltransferase Dnmt3 [38]. Epigenetic mechanisms are responsible for the regulation of polyphenism in insects $[41,42]$ and the existence of these mechanisms is signified by a bimodal distribution of observed/expected CpG ratios $\left(\mathrm{CpG}_{(\mathrm{O} / \mathrm{E})}\right)[38,42,43]$. Bimodally-distributed $\mathrm{CpG}_{(\mathrm{O} / \mathrm{E})}$ ratios indicate the existence of heavily- and lightlymethylated gene groups, with low and high $\mathrm{CpG}_{(\mathrm{O} / \mathrm{E})}$

Table 2 D. noxia De novo genome assembly statistics

\begin{tabular}{lll}
\hline & D. noxia WGS & D. noxia RNA-seq \\
\hline Number of Contigs & $49,379(\geq 1000 \mathrm{bp})$ & $85,990$ ( $\geq 200 \mathrm{bp})$ \\
Number of Scaffolds & 5,641 & $\mathrm{NA}$ \\
Total Contig Length & $293,543,926$ & $99,888,423$ \\
Total Scaffold Length & $393,024,634$ & $\mathrm{NA}$ \\
Contig $\mathbf{N}_{\mathbf{5 0}}$ & 12,578 & 2,863 \\
Scaffold $\mathbf{N}_{\mathbf{5 0}}$ & 397,774 & $\mathrm{NA}$ \\
Largest Contig (bp) & 147,337 & 32,914 \\
Largest Scaffold (bp) & $2,142,037$ & $\mathrm{NA}$ \\
GC/AT percentage & $29.06 \%$ GC/70.94\% AT & $32.8 \% \mathrm{GC} / 67.2 \% \mathrm{AT}$ \\
CEGMA genes & $86.3 \% / 94.4 \%$ & $99.6 \% / 99.6 \%$ \\
(complete/partial) & & \\
\hline
\end{tabular}

De novo genome assembly performed by Allpaths-LG, de novo transcriptome assembly performed by Trinity. ratios, respectively. Divergence of $\mathrm{CpG}_{(\mathrm{O} / \mathrm{E})}$ ratios in each gene group is due to depletion of $\mathrm{CpG}$ dinucleotides over time by the spontaneous deamination of methylcytosine and resulting conversion to thymidine, a process which occurs in all eukaryotes [42-45].

The median CpG composition of $D$. noxia genomic contigs is $2.56 \%$ (ranging from $0.0-13.7 \%$ ) and of predicted transcripts is $2.82 \%$ (ranging from $0.0 \%-19.7 \%$ ) (Additional file 2: Table S2). Genomic contigs contained 15,827,576 CpG dinucleotides, and predicted transcripts contained 1,588,448 CpG dinucleotides. Analysis of $\mathrm{CpG}_{(\mathrm{O} / \mathrm{E})}$ ratios revealed a bimodal distribution (kurtosis $=-1.54$, skewedness $=0.51$ ) with peaks at 0.60 and 1.10 (Figure 1) which is notably similar to those of A. pisum [42], Locusta migratoria [30], and Apis mellifera [43]. In contrast, the unimodal distributions of the holometabolous species Drosophila melanogaster, Nasonia vitripennis, Bombyx mori, Daphnia pulex, and Tribolium castaneum $[38,42]$ indicate the gradual elimination of methylated CpG dinucleotides over time, or the existence of a mechanism which preserves CpG dinucleotides [38]. Peak height comparison reveals that low- $\mathrm{CpG}_{(\mathrm{O} / \mathrm{E})}$ genes are more abundant than high- $\mathrm{CpG}_{(\mathrm{O} / \mathrm{E})}$ genes in both $D$. noxia and $A$. pisum, while the opposite is true in all other examined insects, which are obligately holocyclic and are not morphologically polyphenic [38]. The bimodality of $\mathrm{CpG}_{(\mathrm{O} / \mathrm{E})}$ ratios in $D$. noxia is supported by our finding of a complete DNA methylation gene repertoire, and indicates that DNA methylation is an important regulatory mechanism of gene expression in D. noxia $[38,42,43]$.

\section{Transposable and repetitive elements}

Transposable and repetitive elements are a major component of most insect genomes, although the proportion of the genome occupied by these elements varies by species. Transposable and repetitive element expansions lead to increases in genome size, and may be responsible for speciation events among isolated populations [46-48]. Likewise, reductions in genomic repetitive element proportions are observed in small genomes, potentially as a result of reductions of inefficient genomic elements while maintaining a functional gene complement [31,34,49].

Transposable and repetitive elements make up 15.31\% of the assembled D. noxia genome (Table 3) which is median to the known range for Hemipterans (1\% 


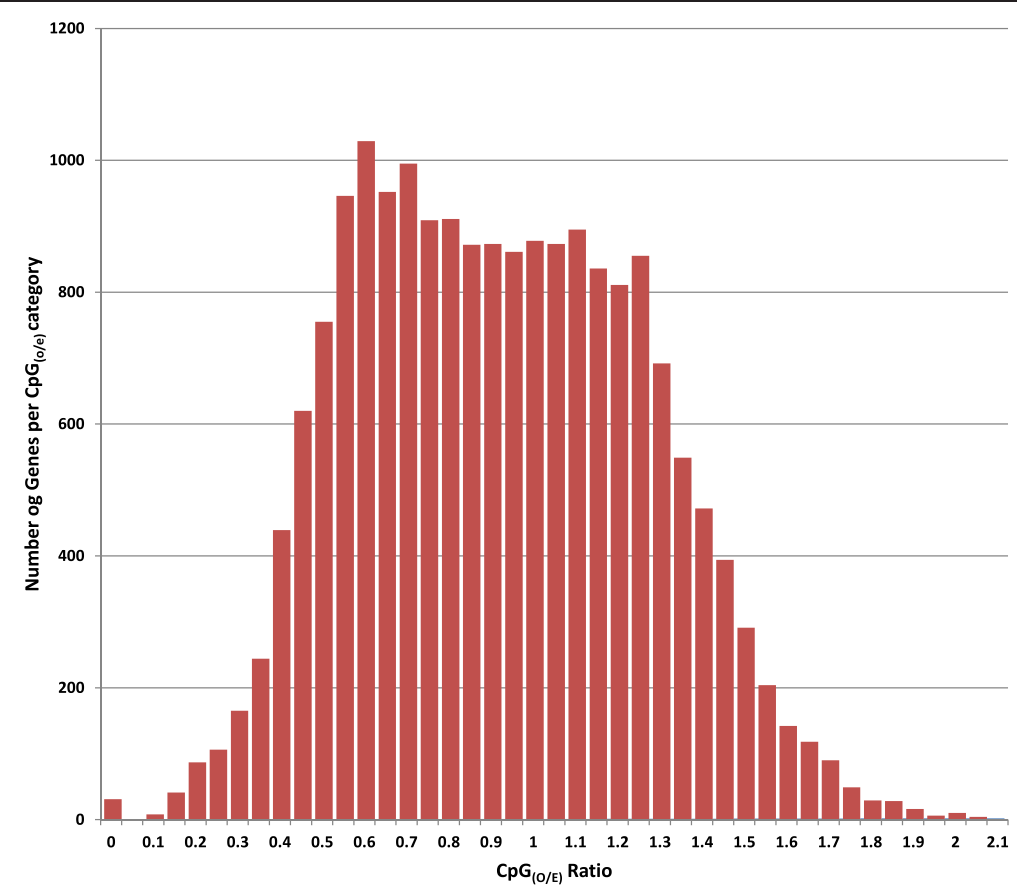

Figure 1 The distribution of observed/expected $\mathrm{CpG}$ dinucleotide ratios among predicted D. Noxia transcripts. CpG(O/E) distributions of all predicted transcripts were determined according to the equation $\mathrm{CpG}_{(\mathrm{O} / \mathrm{E})}=\mathrm{CpG}$ frequency / [C frequency $\times \mathrm{G}$ frequency]. The $\mathrm{CpG}_{(\mathrm{O} / \mathrm{E})}$ distribution of $D$. Noxia is bimodal. $Y=$ number of sequences per category, $X=\mathrm{CpG}_{(\mathrm{O} / \mathrm{E})}$ ratio category (0.05 per category).

Table 3 Summary of transposable and repetitive elements in the $D$. noxia genome

\begin{tabular}{|c|c|c|c|c|}
\hline \multirow{2}{*}{$\begin{array}{l}\text { Element type } \\
\text { SINEs }\end{array}$} & \multirow{2}{*}{$\begin{array}{l}\text { Number of elements } \\
10,729\end{array}$} & \multirow{2}{*}{$\begin{array}{l}\text { Length occupied } \\
2,578,098\end{array}$} & \multirow{2}{*}{$\begin{array}{l}\text { Percentage of } \text { genome }^{\mathbf{A}} \\
0.65\end{array}$} & \multirow{2}{*}{$\begin{array}{l}\text { Percentage of genome } \\
0.87\end{array}$} \\
\hline & & & & \\
\hline ALUs & 0 & 0 & 0 & 0 \\
\hline MIRs & 1 & 58 & 0 & 0 \\
\hline LINES & 8,415 & $1,047,278$ & 0.27 & 0.35 \\
\hline LINE1 & 623 & 33,258 & 0.01 & 0.01 \\
\hline LINE2 & 2,705 & 206,618 & 0.05 & 0.07 \\
\hline L3/CR1 & 695 & 95,452 & 0.02 & 0.03 \\
\hline LTR elements & 6,338 & $1,319,571$ & 0.33 & 0.44 \\
\hline ERVL & 61 & 3,546 & 0 & 0 \\
\hline ERV_classl & 443 & 24,913 & 0.01 & 0.01 \\
\hline ERV_classll & 359 & 17,479 & 0 & 0 \\
\hline DNA elements & 71,820 & $12,373,070$ & 3.13 & 4.17 \\
\hline hAT-Charlie & 3,564 & 466,416 & 0.12 & 0.16 \\
\hline TcMar-Tigger & 139 & 15,935 & 0 & 0 \\
\hline Unclassified: & 70,950 & $14,872,045$ & 3.76 & 5.02 \\
\hline Total Interspersed Repeats & NA & $32,190,062$ & 8.14 & 10.85 \\
\hline Small RNA & 256 & 19,670 & 0 & 0.01 \\
\hline Satellites & 628 & 48,648 & 0.01 & 0.02 \\
\hline Simple repeats: & 246,285 & $11,528,041$ & 2.92 & 3.89 \\
\hline Low complexity: & 31,355 & $1,595,105$ & 0.40 & 0.54 \\
\hline Total: & & $45,381,526$ & 11.47 & 15.31 \\
\hline
\end{tabular}

APercentage of total genome, including $\mathrm{N}$-containing scaffold gaps, occupied by the indicated transposable and repeat elements. ${ }^{\mathrm{B}}$ Percentage of total genome, excluding $\mathrm{N}$-containing scaffold gaps, occupied by the indicated transposable and repeat elements. 
(P. humanus) - 38\% (A. pisum)) [10,34] and of other insect species as well $(0.61 \%$ to $60 \%)[30,31]$. Analysis of repetitive elements in $D$. noxia determined that most repeats are unclassified repetitive elements or DNA elements (5.02\% and $4.17 \%$ of the genome respectively) followed by simple repeats $(3.89 \%)$, SINEs $(0.87 \%)$, low complexity repeats $(0.54 \%)$, LINEs and LTR elements $(0.79 \%)$, and small RNA elements and satellites $(0.03 \%)$. The nearly $50 \%$ reduction in repetitive element percentage in the $D$. noxia assembly is remarkable when compared with $A$. pisum which has an assembled genome only $15.3 \%$ larger than $D$. noxia. High repetitive element percentages correlate with increases in genome size, but not with increased gene content $[31,49]$. Analyses of genome size versus directly measured repetitive element content among 12 insect species $[10,30,31,34,50-56]$ suggests an exponential correlation $\left(\mathrm{y}=14.56 \ln (\mathrm{x})-60.50, \mathrm{R}^{2}=0.742\right)$ (Additional file 3: Figure S1), wherein $D$. noxia's repetitive element percentage is more consistent with a smaller genome size.

\section{Gene and protein model prediction}

Gene and protein models were derived from evidencebased predictions using MAKER software after initially assessing gene predictions from Augustus and MAKER. Augustus predicted 32,440 proteins using Trinityassembled $D$. noxia transcripts as EST evidence, and 25,003 proteins using $A$. pisum transcripts (NCBI refseq) as EST evidence. MAKER predicted 19,097 genes using $D$. noxia RNAseq data as EST evidence, the NCBI pea aphid protein database as supporting data, and the full RepBase repeat database to identify and mask repetitive elements (Table 4). Gene models predicted by AUGUSTUS were more abundant but significantly shorter than MAKER-predicted models, and in some cases, single genes were classified as multiple genes. We chose the more conservative MAKERderived gene model set for all subsequent analyses. The total length of the MAKER-predicted transcriptome was $25,135,138$ bases, or $5.97 \%$ of the genome, within the low end of the range $(1.6-19.4 \%)$ for sequenced insect genomes [31,54]. PFAM analysis of the D. noxia protein set identified 5,799 proteins harboring 27,262 known PFAM domains (Additional file 4: Table S3). RNAseq mapping to the predicted transcript set revealed that 3,608 genes (18.9\%) were not detectably expressed (Additional file 1: Table S1), while a BLASTN comparison $\left(\mathrm{E} \leq 1.0^{-15}\right)$ of Trinity-assembled transcripts vs. MAKER-predicted transcripts determined that 3,313 (17.3\%) predicted transcripts were absent from the RNAseq data. The absence of detected transcription of a portion of $D$. noxia genes indicates that a number of genes may be expressed only under certain environmental or nutritional stresses outside the host plant/environmental conditions we used to rear the insects, or that gene expression occurred at low frequencies in specific tissues, and are best addressed specifically through conducting tissue-specific RNAseq experiments.

Of the 19,097 predicted $D$. noxia genes and their corresponding protein models, 4,867 (25.4\%) produced no BLASTP hits $\left(E \leq 1 \mathrm{E}^{-15}\right)$ against the NCBI Insecta refseq dataset. Similarly, 4,898 D. noxia proteins (25.6\%) were not mapped to orthologous sequences by Ortho-MCL. A BLASTN search $\left(\mathrm{E} \leq 1 \mathrm{E}^{-15}\right)$ of $D$. noxia transcripts $v$ s. the NCBI Insecta refseq gene dataset (obtained 05/07/2014) determined that $4,867(25.4 \%)$ D. noxia transcripts were unique to the species. RNAseq read mapping revealed that 2,624 (53.9\%) of these unique genes were detectably expressed, while 2,243 unique genes were not (Additional file 5: Table S4). The observed percentage of distinct $D$. noxia genes is greater than that of any insect genome sequence published to date. Yet, a similar percentage of unique genes were observed in the Hessian fly Mayetiola destructor, a gall-forming dipteran wheat pest (personal communication, Stephen Richards). Curiously, both $M$. destructor and $D$. noxia alter wheat morphology and physiology, although through differing mechanisms, and this large percentage of unknown genes may reflect a highly evolved parasitic gene-forgene relationship with their hosts $[57,58]$.

\section{Orthology between species}

Orthology analysis of the 19,097 predicted $D$. noxia proteins was performed using ORTHO-MCL on the 150-species ORTHO-MCL database. We assigned 13,402 D. noxia proteins $(70.2 \%)$ to 7,422 ortholog groups, including 5,416 single-copy orthologs, 7,986 multi-copy orthologs, and 797 proteins that matched unassigned orthologs, for a total of 14,199 ortholog group matches. The remaining 4,898 unmatched proteins were mostly hypothetical proteins (Additional file 6: Table S5 and Additional file 7: Table S6). The majority of the 14,199 proteins matched $A$. pisum proteins more closely (81.65\%),

Table 4 Evidence-based and $a b$ initio gene and protein predictions

\begin{tabular}{|c|c|c|c|c|c|c|c|}
\hline $\begin{array}{l}\text { Gene modeling } \\
\text { software }\end{array}$ & $\begin{array}{l}\text { Prediction } \\
\text { method }\end{array}$ & $\begin{array}{l}\text { Transcript/protein } \\
\text { predictions }\end{array}$ & $\begin{array}{l}\text { Ave./median } \\
\text { protein length }\end{array}$ & $\begin{array}{l}\text { Ave./median } \\
\text { transcript length }\end{array}$ & $\begin{array}{l}\text { Longest/shortest } \\
\text { transcript }\end{array}$ & $\begin{array}{l}\text { Total number of } \\
\text { amino acids }\end{array}$ & $\begin{array}{l}\text { PFAM } \\
\text { motifs }\end{array}$ \\
\hline \multirow[t]{2}{*}{ Maker } & Ab Initio & 6,452 & 189 / 138 & $576 / 420$ & 10,278 / 37 & $1,216,145$ & NA \\
\hline & Ab Initio plus Evidence & 12,645 & 439 / 320 & $1,694 / 1,251$ & 29,663 / 66 & $5,548,133$ & 27,262 \\
\hline Total & & 19,097 & 345 / 241 & $1,316 / 831$ & $29,633 / 37$ & $6,764,278$ & 27,262 \\
\hline
\end{tabular}


followed by other arthropods $P$. humanus (3.52\%), B. mori (2.46\%), A. mellifera (2.20\%), Ixodes scapularis (1.41\%), Culex pipiens (1.25\%), Aedes aegypti (1.11\%), D. melanogaster (0.88\%), and Anopheles gambiae (0.82\%) (Additional file 8: Figure S2). Primary matches to 59 additional organisms made up only $4.70 \%$ of the total known orthology designations. Among unmatched proteins, 2,649 individual paralog pairs (Additional file 9: Table S7) were identified that grouped into 357 in-paralog families containing 1,337 proteins (Additional file 10: Table S8). The three largest in-paralog families contained 35 proteins each and the smallest (207 separate groups) held two proteins each. Inparalog families were identified through comparisons to 150 separate species to ensure the greatest level of discrimination and produce the most $D$. noxia-specific in-paralog group possible.

D. noxia and A. pisum share 7,072 common ortholog groups which included 2,290 single-copy genes present in both species. Ortholog groups present in $D$. noxia and A. pisum, when compared to other selected arthropod species (A. gambiae, I. scapularis, A. mellifera, D. melanogaster, B. mori, and $P$. humanus), revealed an increasing distance between aphids and other insects or arthropods (Figure 2 and Additional file 11: Figure S3). Of the 7,072 ortholog groups shared between $D$. noxia and A. pisum, 3,839 were common to all eight arthropods (Figure 2A). Of the remaining 3,233 OGs not common to all examined species, 430 were exclusive to $D$. noxia and $A$. pisum, and D. noxia possessed 134 OGs not observed in any of the other species (Figure 2B).
Probing the relationship of $D$. noxia and A. pisum to other individual arthropod species (Additional file 11: Figure S3) found a maximum of 5,990 OGs in common with $P$. humanus and a minimum of 5,021 in common with I. scapularis. Evaluations of the orthological relationship between $D$. noxia and $A$. pisum and more distantly related organisms revealed fewer common ortholog groups, with a minimum of 2,378 groups in common with bread mold, Neurospora crassa (Additional file 11: Figure S3).

The phyletic relationship between $D$. noxia and other arthropod species $[10,28,34,56,59,60]$ was examined by constructing a maximum-likelihood phylogeny from concatenated alignments of 37 single-copy proteins unique to arthropods (Figure 3A). Results confirmed those of previous insect phylogenetic analyses $[2,10,11,33,53,55]$ that demonstrate an ancient branch point between insects and arachnids and an early divergence between paraneopteran insects represented by the hemimetabolic insects $D$. noxia, $A$. pisum, and $P$. humanus, and the remaining holometabolic insects. Furthermore the accurate placement of this aphid in the phylogeny of other insect groups validates the robustness of the $D$. noxia genome assembly and gene predictions.

Direct examination of orthological relationships between each species (Figure 3B) determined that of the common 3,839 OGs, 401 OGs were present in 1:1:1 relationships and 145 OGs had N:N:N relationships in all examined species, allowing no gene losses within individual species. The remaining 3,293 OGs were present
A

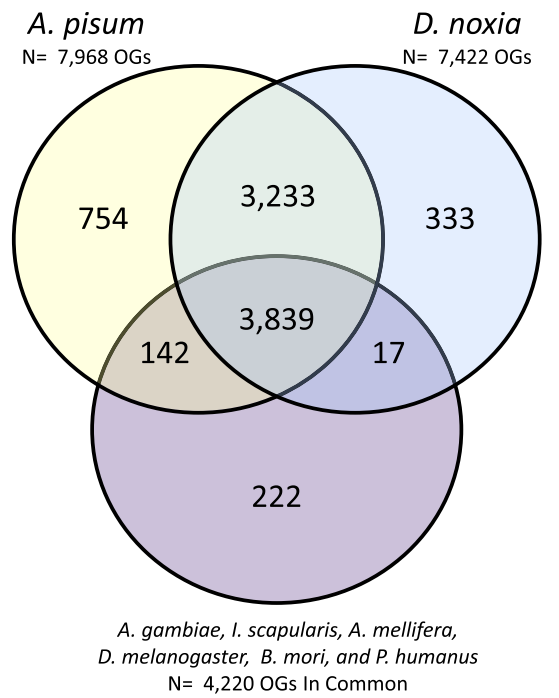

B

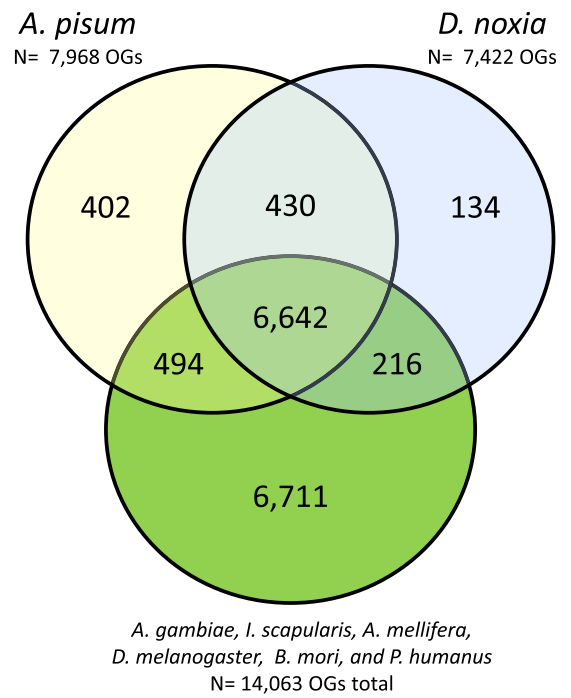

Figure 2 Comparison of orthology among arthropod species. A. Ortholog groups common to A. gambiae, I. scapularis, A. mellifera, D. melanogaster, B. mori, and P. humanus (present in all six species) in comparison to ortholog groups present in D. noxia and A. pisum. B. Ortholog groups present in at least one of the named species compared to ortholog groups present in D. noxia and A. pisum. 


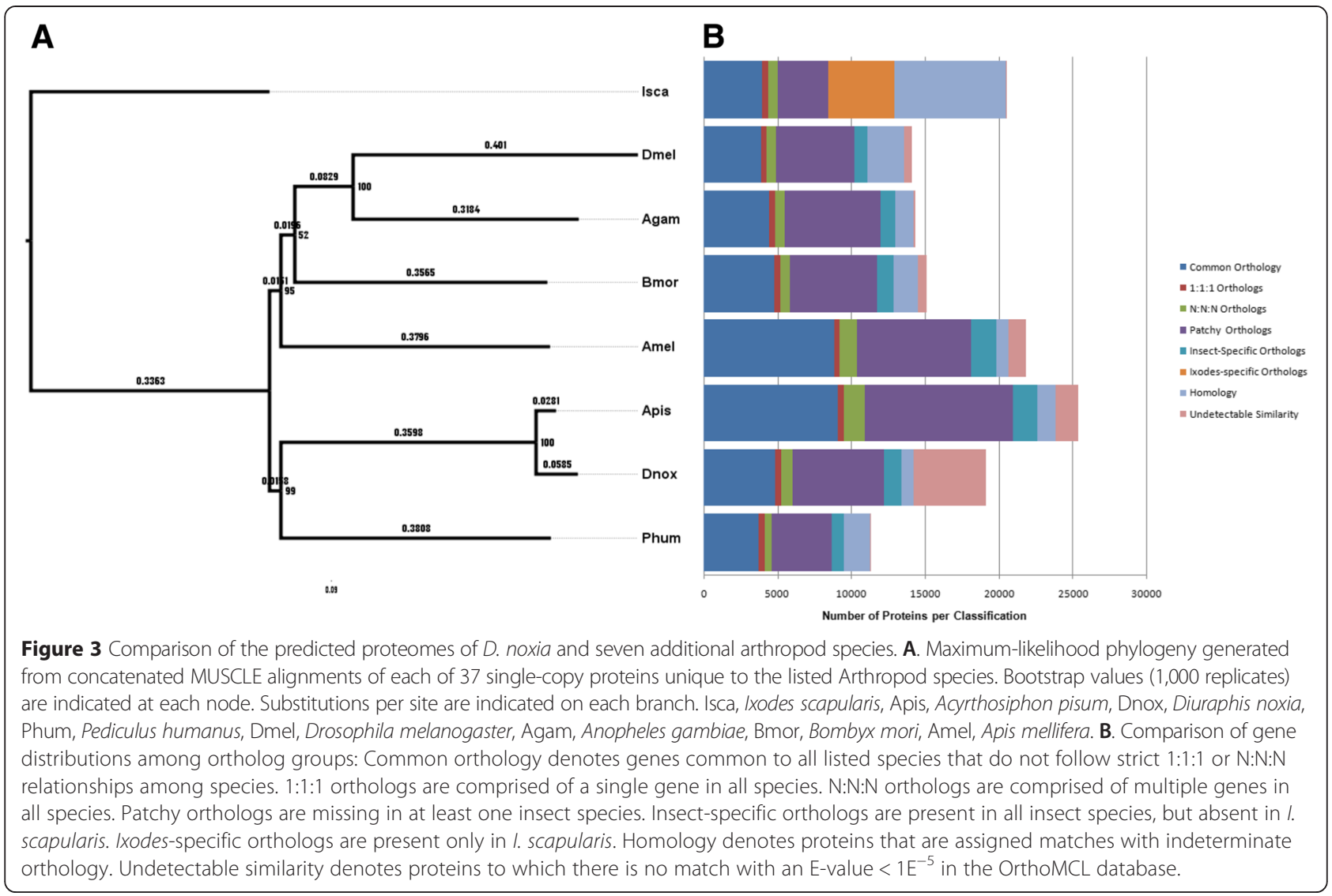

in either single or multiple copies in each species, and were classified as common orthologs. Ortholog groups with losses among species, including species-specific OGs, were classified as patchy orthologs which includes 752 ortholog groups unique to insects with varying numbers of members in each species, while 2,011 OGs $(4,454$ proteins) were present only in $I$. scapularis. The remaining proteins for each species were classified either as homologous proteins not yet placed into orthologous groups, or as unclassified proteins with no acceptable match in the orthology database. The pattern of orthology classification in D. noxia is similar to other insect species, yet with a larger percentage of unclassified genes $[10,28,31,34,53,56,60,61]$. By disallowing orthology group losses we present the most strict representation of orthologous relationships.

\section{Lineage-specific expansions}

Lineage-specific expansions (LSEs), reductions, and deletions for $D$. noxia versus $A$. pisum were analyzed by comparing Ortho-MCL analyses of their predicted proteomes. A previous LSE comparison of $A$. pisum with $P$. humanus revealed a large number of aphid specific expansions [10], and genomic expansions correspond with host race evolution in A. pisum [62,63]. Comparisons of gene copies per ortholog group between $D$. noxia and $A$. pisum found that most common ortholog groups contained identical gene numbers in each species. However, A. pisum possessed a larger number of expanded gene families (Figure 4, Additional file 12: Table S9, Additional file 13: Table S10, and Additional file 14: Table S11). D. noxia exhibited 1,022 lineage-specific ortholog group expansions, including 672 expanded groups (1,777 additional genes) and 350 novel groups not present in $A$. pisum. A. pisum had 4,591 ortholog group expansions, including 3,694 expanded groups (9,835 additional genes) and 895 ortholog groups not present in D. noxia. A total of 3,004 ortholog groups (3,261 individual genes) had equal numbers of members in $D$. noxia and $A$. pisum, including 2,290 1:1 orthologs and $413 \mathrm{~N}: \mathrm{N}$ orthologs (Figure 4). Four of the five largest RWA-specific expansions were in ortholog groups associated with transposable and retrotransposable elements and an unclassified gene family, a pattern also noted in A. pisum [10], while the fifth largest expansion occurred in a zinc finger-associated ortholog group (50 additional genes) (Additional file 12: Table S9 and Additional file 13: Table S10). Additional large D. noxia ortholog group expansions included FTsJ-like methyltransferase (34 additional genes), zinc-finger proteins (78 additional genes 


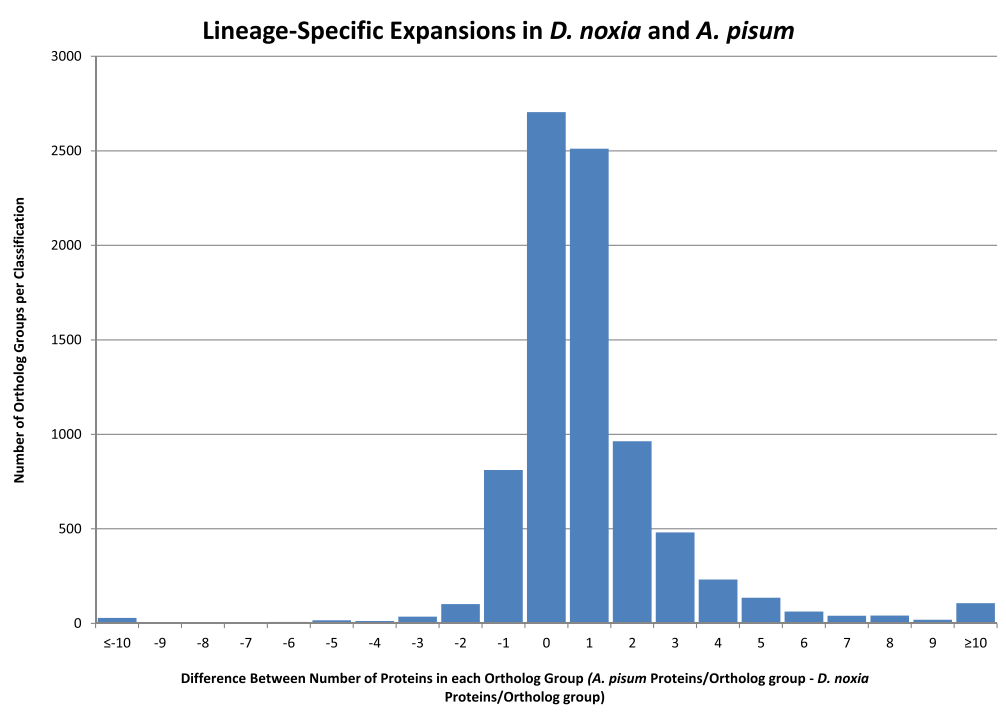

Figure 4 Lineage-specific expansions of ortholog groups between D. noxia and A. pisum, including ortholog groups unique to each species. The number of proteins contained within each ortholog group in A. pisum was subtracted from the number of proteins in the identical ortholog group in D. noxia. Negative numbers indicate lineage-specific expansions in D. noxia, and positive numbers indicate lineage-specific expansions in A. pisum.

in three groups), and alcohol dehydrogenase transcription factors (27 additional genes in three groups). In contrast, the five largest pea aphid lineage-specific expansions were Kelch proteins (286 additional genes), a retrotransposon peptidase (183 additional genes), two unclassified gene families (92 and 89 additional genes), and a zinc finger protein (79 additional genes).

A. pisum is thought to have undergone extensive gene duplication during its evolution [10], which our LSE comparisons with $D$. noxia affirm. The general decrease in duplications per ortholog group, and the lower abundance of ortholog groups, in $D$. noxia versus $A$. pisum suggests that the $D$. noxia genome has been subject to relatively less alteration over the course of its evolution. D. noxia's relative lack of gene duplications and expansions may indicate that $D$. noxia maintains and increases it host range by means other than genomic alteration or gene family expansion $[47,48,62,63]$.

\section{Feeding-related genes}

Aphid feeding requires a balance of specific salivary components to suppress or mitigate plant defenses throughout the stylet probing and feeding processes to allow sustained feeding on host plant phloem $[64,65]$. The invasive nature of plant feeding by aphids requires the expression of an array of salivary and metabolic genes that act upon the plant and protect the aphid from plant defensive proteins and xenobiotics [3,64-69]. D. noxia is unique among most aphids in that the saliva it injects while feeding produces phytotoxic symptoms that alter plant morphology and progressively damage the host to enrich phloem nutrition
[14,69-71]. In accordance with the differences in host range between aphid species, feeding-related genes would certainly be subject to variation among and within species, therefore, salivary protein profiles are distinct to aphid species, biotypes, and host races [69,72-76].

\section{Salivary genes}

We discovered 29 of 34 salivary genes previously detected in proteomic analyses of four $D$. noxia biotypes in this genome assembly [69]. Five genes that were not detected were the D. noxia orthologs of GJ23220, IscW_ISCW012834, IP06594, Lava Lamp, and mitochondrial cytochrome c oxidase subunit I (COI). However, the mitochondrial COI gene was noted among the RNAseqpredicted transcripts, but was excluded from the genome assembly by the high-molecular weight DNA extraction method utilized. The remaining absent proteins may represent unassembled portions of the $D$. noxia genome, or may have sequences that are significantly altered outside of the original identified peptides [69].

A BLASTP examination comparing each predicted $D$. noxia salivary protein sequence to the NCBI Insecta refseq protein database revealed that each $D$. noxia salivary protein was more closely related to an $A$. pisum counterpart than to proteins from any other species, with $\mathrm{E}$ values ranging from 0.00 to $6.22 \mathrm{E}^{-74}$ and identities ranging from $100 \%$ to $58.21 \%$ (Additional file 15 : Table S12 and Additional file 16: Table S13). The level of homology between $D$. noxia salivary protein sequences and their corresponding $A$. pisum orthologs varied inversely with the apparent abundance of each protein in 
the saliva [69]. Common insect salivary proteins such as glucose dehydrogenase, trehalase, and apolipophorin were among the proteins with the least homology to their $A$. pisum orthologs. In contrast, those $D$. noxia salivary proteins that have not been observed in the saliva of other insects exhibited greater homology with orthologs from A. pisum and other insect species (Additional file 15: Table S12 and Additional file 16: Table S13) $[69,73]$. This finding implies that salivary gene expression, rather than sequence divergence, may play a role in $D$. noxia's host specificity and phytotoxicity.

Glucose dehydrogenase and apolipophorin are among the most common and abundant proteins in aphid saliva $[66,69,73,74]$. Multiple glucose dehydrogenase proteins are present in aphid saliva, but their differing amino acid compositions suggest that each protein performs a different function within the plant host. Apolipophorin, present as a single gene copy in D. noxia, A. pisum, and most other insect species, was used to examine the phylogenetic relationship of $D$. noxia with other arthropods from the perspective of a conserved single-copy gene. A maximum-likelihood phylogenetic tree derived from a MUSCLE alignment of apolipophorin from eleven arthropod species confirmed known phylogenetic patterns, with basal branching of the aphid lineage from the holometabola and a more recent divergence of $D$. noxia and A. pisum (Additional file 17: Figure S4).

\section{Defensive and detoxifying genes}

Insects possess a suite of defensive and detoxification genes in order to cope with constitutive and induced host defensive compounds and xenobiotics, [65-68]. The most important insect defense and detoxification genes include $\mathrm{ABC}$ transporters (ABCt), cytochrome P450s (CYP450), glutathione-s transferases (GST), and carboxyl and choline esterases (CCE) $[30,33,53,77]$. D. noxia possesses $53 \mathrm{ABCt}, 48 \mathrm{CYP} 450,11 \mathrm{GST}$, and $8 \mathrm{CCE}$ genes, compared to $113 \mathrm{ABCt}, 85 \mathrm{CYP} 450,28 \mathrm{GST}$, and 29 CCE genes in A. pisum (Additional file 1: Table S1, Additional file 12: Table S9, and Additional file 16: Table S13). We performed a phylogenetic analysis of CYP450 protein sequences from $D$. noxia and $A$. pisum in order to examine the relationship between the two species. CYP450 proteins from each species, representing CYP clans 2, 3, and 4, as well as the mitochondrial CYP clan, grouped together, validating the accuracy of the assembly and annotations, as well as demonstrating an evolutionarily close relationship between the two species (Figure 5). The close relationship between D. noxia and A. pisum is further demonstrated by the $89.2 \%$ median similarity between CYP450s from the two species. Although five D. noxia CYP450s belonged to the mitochondrial clan, the $D$. noxia mitochondrial genome contains no CYP450 sequences [78], nor did BLASTP analysis reveal the presence of any $D$. noxia mitochondrial proteins in this assembly. Thus each mitochondrial CYP450 sequence noted in the $D$. noxia genome may represent an instance of horizontal gene transfer during the early evolution of its primordial aphid ancestor. GSTs had a median 92.1\% identity between the two aphid species, and CCEs had a median $91.2 \%$ identity between the two aphid species. The reduced number of defensive and detoxification proteins for $D$. noxia may reflect a greater role of phytotoxic salivary effects and decreased reliance upon physiological and metabolic countermeasures to host defenses in comparison with A. pisum and other insects in general.

\section{Chemoreceptors}

Chemoreception genes are critical in perceiving taste and odor stimuli in order to locate appropriate food sources and establish feeding. Duplication or mutation of chemoreceptor genes can alter feeding behavior, and is implicated in insect speciation $[48,62,63]$ and in establishing host range [79]. The $D$. noxia genome contains 30 gustatory receptors (GR), 21 odorant receptors (OR), and 9 odorant binding proteins (OBP) (Additional file 16: Table S13), while $A$. pisum has 77 GRs, 79 ORs, and 15 OBPs [62] and Aphis gossypii, a generalist feeder, has 45 ORs, but an unreported GR and OBP number [80]. Another Hemipteran insect, $P$. humanus, has only 10 ORs, 5 OBPs, and 8 GRs, a condition suspected to result from host range restriction [34]. Omnivorous insect species also have a much higher number of chemoreceptors; the omnivorous $T$. castaneum possesses 265 ORs and 220 GRs [33], the housefly Musca domestica has 52 OBPs, 62 ORs, and 68 GRs [81], and the hymenopteran nectar-feeder $A$. mellifera has 170 ORs and 21 OBPs, but only 10 GRs [28]. Comparison of OR numbers across insect species is complicated by the fact they include receptors to detect sexual pheromones that are essential to reproduction. Accordingly, high sequence variability was found between the ORs of $D$. noxia and $A$. pisum, ranging from $95 \%$ to $28 \%$ identity with the corresponding $A$. pisum OR sequence. Substantial sequence variation was also noted between $A$. gossypii and $A$. pisum ORs [80], indicating their potential role in host selection. The scarcity of $D$. noxia chemoreceptors in comparison with $A$. pisum and A. gossypii suggests that taste and odor perception may be less important in food source selection for $D$. noxia. Reductions in chemoreceptor numbers suggests that $D$. noxia relies upon phytotoxic salivary proteins to overcome host defenses and enhance the nutritional value of its hosts, thereby reducing its reliance upon chemoreceptors to identify suitable hosts and to broaden its host range [70,71].

\section{Sugar transporters}

Aphids consume a sugar-rich diet with a high osmotic potential, requiring only proteins such as uniporters that 


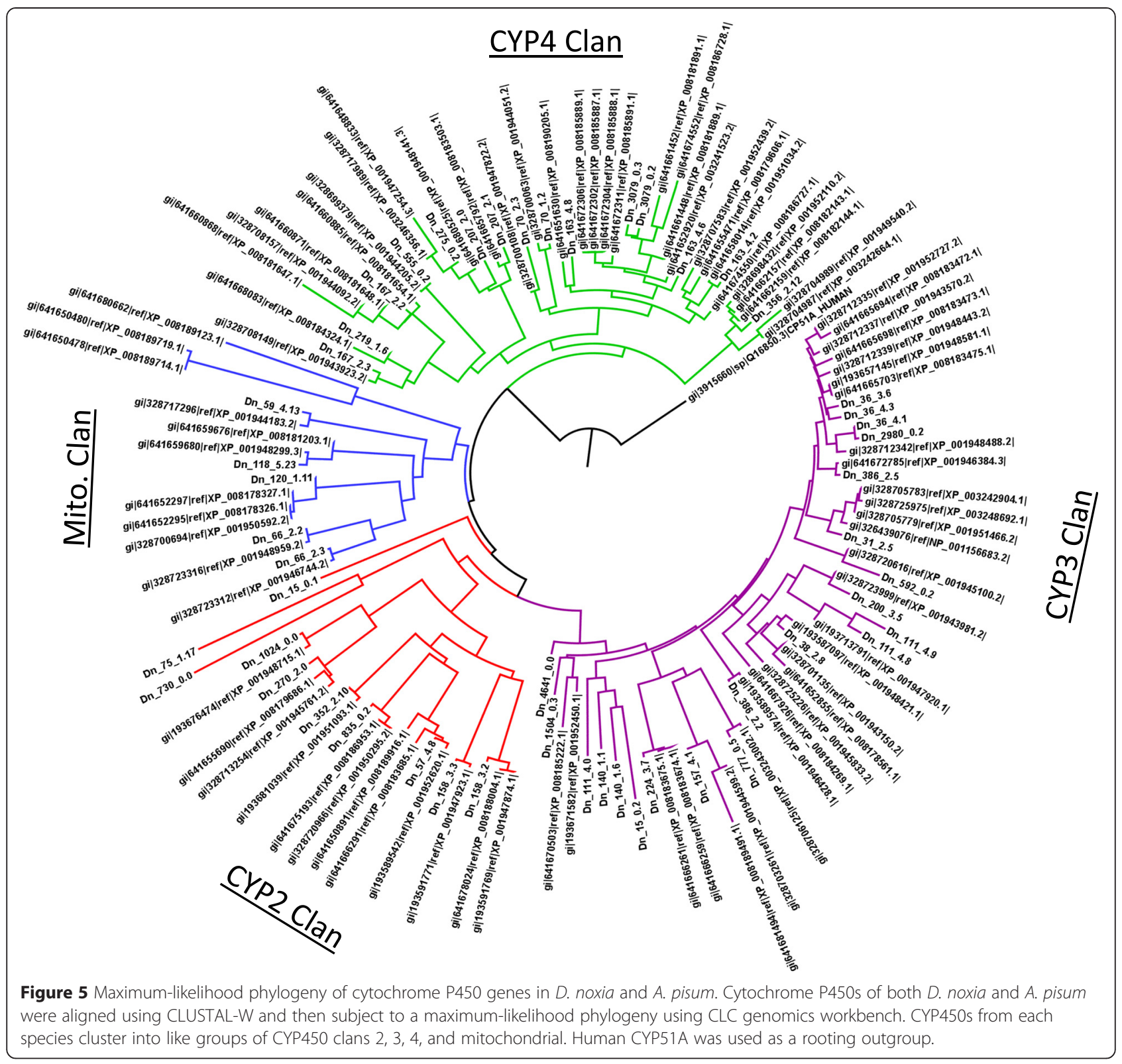

allow movement of phloem sugars with the membrane concentration gradient and into the hemolymph [10]. The $D$. noxia genome contains a number of sugar transporters, including 84 Major facilitator genes compared with 200 in $A$. pisum and 13 inositol/glucose/sugar transporters versus 34 in pea aphid [10] (Additional file 16: Table S13). It is hypothesized that the relative increase in A. pisum sugar transporters in comparison to other sequenced insects reflects the adaptation to a sugar-rich diet [10]. D. noxia has a lower number of sugar transporters $D$. noxia relative to $A$. pisum, revealing that sugar transporter gene expansion is not a universal condition in aphids and varies by hosts they utilize.

\section{RNAi and epigenetic pathways}

The RNA regulatory pathway, which includes the RNA interference (RNAi) and epigenetic regulatory pathways, functions in viral defense and gene regulation by degrading aberrant RNA and establishing and maintaining DNA and chromatin methylation. These mechanisms are not present in all insect lineages $[41,42,82]$, and are notably lacking in D. melanogaster [38]. Regulation of gene expression by DNA methylation is an essential aspect of polyphenism in aphids and other insects [41,42]. Likewise, $D$. noxia possesses the components of the common insect RNAi and epigenetic pathways [41,82-84]. Single copies of the genes SID1, AGO3, DCR-1, DCR-2, Drosha, Pasha, vacuolar H + -ATPase, Exportin-5, HEN1, 
Loquacious, and R2D2 were found, along with five PIWI, two PRMT-5, two AGO1, and two AGO2 genes (Additional file 16: Table S13). Genes required for epigenetic DNA and chromatin modifications were also present, including six Type 1 and 3 DNA methyltransferases, 16 histone-lysine methyltransferases, and 10 histone deacetylases (Additional file 16: Table S13). The presence of RNAi, DNA methylation, and chromatin methylation pathway components in $D$. noxia, in conjunction with the existence of a bimodal $\mathrm{CpG}_{(\mathrm{O} / \mathrm{E})}$ distribution ratio (Figure 1), confirms that $D$. noxia genes are subject to regulatory methylation similar to A. pisum and A. mellifera $[38,43]$.

\section{Insecticide resistance pathways}

Most insecticides target specific protein motifs, and lose efficacy when mutations or alternate isoforms of the target protein prevail throughout a pest population. $D$. noxia is resistant to many insecticides in comparison to other insects [85], but is effectively controlled by systemically-applied pyrethroid, organophosphate, and organochlorine insecticides [86]. The emergence of new $D$. noxia insecticide resistance has not been reported, but the aphids Myzus persicae, Aphis gossypii, and Schizaphis graminum have each developed resistance to several previously-effective insecticides [87-89].

D. noxia possesses common insecticide targets including an acetylcholinesterase-1 ortholog with S431 pirimicarb susceptibility, four additional acetylcholinesterases, 21 acetylcholine receptors, 12 sodium channel genes, and five GABA receptors, but neither neonicotinoid-detoxifying CYP450 (CYP2A6 and CYP6CY3) [88] (Additional file 15: Table S12). The absence of reported insecticide resistance in $D$. noxia is likely due to past reliance upon host resistance instead of insecticides. However, $D$. noxia displays significant chromosomal heterogeneity and rapid biotype development under the selection pressure of plant resistance genes, making it likely that genetically-based insecticide resistance can occur under high selection pressure. D. noxia's smaller complement of detoxifying genes in comparison with other insects, exemplified by the absence of CYP2A6 and CYP6CY3, further suggests that such resistance will most likely occur as a result of a mutationbased sequence shift [90], rather than through amplified expression of a rare transcript [87], although both mechanisms are possible.

\section{Virus transmission}

The majority of aphid-related plant damage is through plant virus transmission during feeding, and most grain aphid species are significant vectors of the barley yellow dwarf virus [91]. D. noxia is exceptional in that it does not transmit plant pathogenic viruses [18]. Nevertheless, the genome of $D$. noxia possesses a full complement of proteins thought to be involved in viral transfer, including 10 dynamins, 8 serine protease inhibitors, 8 vesicle transport/trafficking proteins, and 15 cyclophilins [10,15] (Additional file 16: Table S13). As viruses interact with specific epitopes of proteins involved in trans-membrane transport, it is likely that protein sequence differences between $D$. noxia and virus-transmitting aphids do not favor viral attachment. The inability of $D$. noxia to vector viruses requires further exploration.

\section{Genes laterally transferred from bacteria}

Aphids are obligate parasites that are able to feed upon nutritionally-deficient phloem sap through an endosymbiotic relationship with Buchnera aphidicola. These bacteria are housed within specialized bacteriocytes in the aphid gut lining and produce essential amino acids lacking in the host plant phloem [92]. B. aphidicola displays limited sequence and gene copy number variance between $D$. noxia biotypes, and it is hypothesized that variance in total endosymbiont and plasmid copy number impacts aphid fitness [92,93]. The $D$. noxia genome holds genes that originated from the genome of $B$. aphidicola and that represent horizontal gene transfer from the $B$. aphidicola genome to the $D$. noxia genome. These include one LD carboxypeptidase and one rare lipoprotein receptor (RlpA) (Additional file 16: Table S13) as found in A. pisum $[10,94,95]$, but not the acetylmuramidases noted in A. pisum [10]. These genes were each located within long contigs $(>5,000$ bases in length) that included additional $D$. noxia genes not derived from the endosymbiont. As in A. pisum, there is no evidence of extensive horizontal gene transfer in the $D$. noxia genome [10]. The DNA extraction and D. noxia pre-assembly read filtering method removed reads matching the B. aphidicola assembly originating from $A$. pisum, thereby eliminating the endosymbiont genome from our analysis, as supported by the absence of mitochondrial sequence in this assembly, and thus it is not addressed.

\section{Conclusions}

$D$. noxia's genome shares many genes in common with the current model aphid, A. pisum, but varies in genome size and architecture, and specific functional genetic processes. The $D$. noxia genome, with its moderate transposable and repetitive element component and fewer total genes and gene families than are present in A. pisum [10], presents a case for a high degree of genomic conservation over time. The reduced repetitive element percentage in the $D$. noxia genome may factor in the lower number of gene family expansions relative to A. pisum [55], and is consistent with the hypothesis that insect evolution is driven by transposable element expansion and gene duplication $[10,53,55,63]$. The $D$. noxia genome also differs from that of $A$. pisum, primarily 
in genes governing host detection, acceptance, and feeding processes. This genome assembly describes $D$. noxia as a species uniquely adapted to feed upon graminaceous hosts using its salivary proteins to alter host morphology and metabolism [69-71], and provides an important contrast to non-phytotoxic aphids that depend on metabolically countering plant defensive compounds $[3,66,67]$.

D. noxia possesses a low number of chemoreceptor genes compared to other insects $[10,53,55,60,80]$ suggesting it has a low reliance on taste and odor perception as a survival criterion. It also has significantly fewer detoxifying and defensive genes in comparison with $A$. pisum and other insects [10,33,81], implying that $D$. noxia has evolved another way to circumvent host defenses. $D$. noxia's relatively wide host range and rapid establishment into new geographical areas indicates that D. noxia's genomic deficiencies in feeding-related genes in comparison to $A$. pisum are compensated for, and overcome by, phytotoxic salivary proteins that drive phloem nutrition enrichment and alter host morphology [14,69-71]. Aphids causing phytotoxic reactions in plants are uncommon, thus $D$. noxia is an exception to the typical view of insect-plant coevolution, in which aphid evolution is thought to be driven by the necessity to avoid or detoxify newly-evolving plant defensive responses in order to feed without damaging the host [96,97]. D. noxia presents a more rapacious character, surviving by inducing phytotoxic symptoms which damage and eventually destroy its host.

Our assembly presents a phytotoxic aphid model as an alternative genomic model for aphids and represents the second sequenced aphid genome. The contrasting and divergent evolutionary paths of $D$. noxia and $A$. pisum, and their contrasting aphid-host relationships, provide an extraordinary opportunity to better address the genetic basis of the feeding processes of aphids and their ability to evade plant defenses, to understand the nature of interactions between aphid virulence genes and plant resistance genes, and to formulate comparative and functional genomics studies that will ultimately lead to increased knowledge of aphid biology and evolution.

\section{Methods}

\section{DNA and RNA collection, sequencing, and assembly}

Chromosomal DNA was collected using the Agilent DNA extraction kit from a pooled sample of 200 Diuraphis noxia Biotype 2 adult females isolated from a single clone-derived colony obtained from the USDA-ARS Cereal Insects Genetic Resource Library (CIGRL, Stillwater, OK) reared on wheat cv. TAM110. Total RNA was also recovered from 200 pooled RWA2 adult females from the same source, and extracted using the Promega SV Total RNA Isolation system. Recovered DNA and RNA was frozen at $-80^{\circ} \mathrm{C}$ immediately and used in subsequent sequencing analyses. The recovered DNA was sheared into paired-end and mated-pair libraries (Corvaris S2, Paired-end: peak power 50.0, duty factor 10.0, cycle per burst 200, time per run 90 s; Mated-pair: duty cycles 20\%, intensity 0.1 , cycle per burst 100 , time per run $5 \mathrm{~min}$ ), and purified (Paired-end: Dynal magnetic M 280-streptavidin beads, Mated-pair: Agencourt AMPure XP beads). Pairedend reads were then end-repaired, A-tailed, and ligated to adapters, then amplified by PCR $\left(98^{\circ} \mathrm{C}\right.$ for 30 s, 18 cycles of: $98^{\circ} \mathrm{C} 10 \mathrm{~s}, 65^{\circ} \mathrm{C} 30 \mathrm{~s}, 72^{\circ} \mathrm{C} 30 \mathrm{~s}$, with a final step of $72^{\circ} \mathrm{C}$ $15 \mathrm{~m}$ and $4^{\circ} \mathrm{C}$ until retrieved). Agencourt AMPure XP beads were used for purification following PCR. Sequencing was performed with an Illumina Hiseq 2000 with TruSeq v3.0 chemistry. Paired-end fragments, prepared by the U.S. National Institutes of Health/National Cancer Institute, averaged 223 bases with a read length of $2 \times 101$ bases. A mated-pair library prepared by the NIH/NCI averaged $2.6 \mathrm{~kb}$ in length, also with a read length of 2x101 bases. An additional mated-pair library was created by Axeq Technologies, Inc. (Rockville, MD) averaging $8.7 \mathrm{~kb}$, with a read length of $2 \times 101$ bases. All reads were quality filtered on the basis of each read containing a minimum of $90 \%$ of bases in each read having a minimum quality score of Q20. Reads were additionally filtered before assembly by removing those reads mapping to the $A$. pisum endosymbiont Buchnera aphidicola genome. The qualityand Buchnera-filtered reads were then used as input for the genome assembly program AllPaths-LG $[98,99]$, which was used to conduct a de novo assembly of the RWA2 genome using default settings, with inward-oriented paired-end libraries and outward-oriented jumping libraries, and with ploidy set to 2 (diploid).

RNA-seq was performed by NIH/NCI, $1 \mu \mathrm{g}$ of RWA2 RNA per lane was processed according to the Illumina Truseq RNA Low-sample preparation protocol and sequenced using paired-end reads $(2 \times 101)$ on an Illumina Hiseq 2000 using Truseq v 3.0 chemistry. Reads were quality-filtered prior to assembly to include only sequences with a Q20 value in greater than 90\% of bases, and these reads were used to perform a de novo transcriptome assembly using the TRINITY (r2012_10_05) software package using default settings (Broad Institute, Boston, MA) [100]. The assembled sequences were used downstream for evidence during genome annotation, and RNAseq reads were mapped to predicted transcripts using CLC genomics workbench v. 7.5.

\section{Transposable and repetitive element analysis}

The RWA genome scaffolds were used to determine the repeat content of the RWA2 genome by analysis with RepeatMasker 4.0.3 [101]. The RWA scaffold file was analyzed using first RepeatModeler [102] to identify RWA-specific repeats. Masked sequences were then analyzed with RepeatMasker, run with the RepBase full repeat database 
(Repbase18.07) as an evidence file, to identify all repeats and transposable elements within the $D$. noxia genome.

\section{Structural prediction and genome annotation}

Structural genome annotation was performed by utilizing RWA2 genomic scaffolds as input for the MAKER [103] genome annotation pipeline. RepeatMasker was used to mask low-complexity regions and repetitive DNA using the custom database created during repeat masking [101]. The following evidence files were used to aid in annotation: EST/RNA sequence evidence was provided by RWA2 Trinity-assembled RNA seq data, repetitive sequences were provided by the combined $D$. noxial RepBase repeat database and protein data was provided by the $A$. pisum refseq protein dataset (NCBI refseq, downloaded 03/15/14). Augustus [104] was used within the MAKER framework to develop ab initio protein and transcript predictions. PFAM analysis was conducted using an HMM-based search (CLC Genomics version 7.0) of all MAKER-derived protein models using the full PFAM database (version 22.0). Transcripts and proteins predicted by MAKER were subjected to BLASTN and BLASTP comparisons using the CLC Genomics workbench (v. 7.0).

\section{Genomic analyses}

Ortho-MCL [105] was used to determine the orthology of the 19,097 MAKER-identified RWA2 proteins and the NCBI protein refseq databases for $D$. melanogaster (14,067), A. pisum (24,378), A. mellifera (21,780), P. humanus $(11,336)$, A. gambiae $(14,341)$, B. mori $(15,068)$, and I. scapularis $(20,467)$ as comparison species. Orthologous groups were determined utilizing the Ortho-MCL web service (orthomcl.org). First, an all-vs-all BLASTP of each species-specific database was performed against the full OrthoMCL database (150 species, accessed 07/15/ 2014), followed by determination of orthologs, paralog pairs, and in-paralog groups. Results from each of these analyses were compared directly to discover multiple- and single-copy orthologs between species. In order to compare single-copy orthologs between species, 37 single-copy orthologs specific to this arthropod group, and absent from any other organism, were retrieved from the ORTHO-MCL database and aligned using MUSCLE [106]. The resulting alignments were concatenated by CLC genomics workbench (v. 7.0). Concatenated alignments were used to construct a maximum-likelihood phylogeny by neighbor-joining analysis over 1,000 replicates, also using the CLC genomics workbench (v. 7.0). Additional phylogenetic analyses were conducted using MUSCLE or CLUSTAL-W alignments to produce maximum-likelihood phylogenies by neighbor-joining analysis with the CLC genomics workbench (v. 7.0)

Nucleotide and dinucleotide content of the genome and predicted transcripts was conducted using Sequool software package. Percentages of each nucleotide per scaffold or transcript were analyzed, as were the percentage of CpG dinucleotides. CpG dinucleotide observed/ expected ratio was performed for each transcript using the formula $\mathrm{CpG}_{(\mathrm{O} / \mathrm{E})}=\mathrm{CpG}$ frequency $/(\mathrm{C}$ frequency $\times \mathrm{G}$ frequency) [43].

\section{Data access}

The Whole Genome shotgun project was deposited with the National Center for Biotechnological Information (NCBI) under accession number JOTR00000000, Bioproject PRJNA233413. Raw Illumina DNA reads were submitted to the NCBI SRA database under the Biosample number SAMN02693874, RNAseq reads were submitted under biosample number SAMN03435929. Illumina reads may be accessed under SRA study SRP040557.

\section{Additional files}

Additional file 1: Table S1. Expression of individual genes in FPKM as measured by mapping of RNAseq reads against predicted $D$. noxia gene sequences.

Additional file 2: Table S2. CpG frequencies and observed/expected ratios among predicted $D$. noxia transcripts.

Additional file 3: Figure S1. Analysis of genome size versus repetitive element content of selected arthropods.

Additional file 4: Table S3. PFAM domains identified in predicted D. noxia proteins.

Additional file 5: Table S4. RNAseq read mapping of genes unique to D. Noxia.

Additional file 6: Table S5. Predicted D. Noxia genes with orthologous matches. The orthology classifications, top orthologous matches, and number of genes per ortholog group are included.

Additional file 7: Table S6. Orthology analysis of complete D. noxia gene set.

Additional file 8: Figure S2. Distribution of top hits to $D$. noxia genes. Additional file 9:Table S7. Paralog pairs identified during orthology analysis of predicted $D$. noxia proteins.

Additional file 10: Table S8. In-paralog groups identified from merged paralog pairs.

Additional file 11: Figure S3. Venn diagrams describing orthology relationships between $D$. noxia, A. pisum, and each indicated species.

Additional file 12: Table S9. Lineage-specific ortholog group expansions, reductions, and deletions between D. noxia and A. pisum.

Additional file 13: Table S10. Lineage-specific ortholog group expansions and reductions between D. noxia and A. pisum.

Additional file 14: Table S11. Ortholog group deletions among $D$. noxia and A. pisum.

Additional file 15: Table S12. BLASTP analysis of previously-detected D. noxia salivary protein-coding genes.

Additional file 16: Table S13. List of genes comprising the functional groups identified in D. noxia Biotype 2.

Additional file 17: Figure S4. Phylogeny of apolipophorin among selected species.

Abbreviations

G + C: Guanine + Cytosine; A + T: Adenine + Thymidine; SNP: Single nucleotide polymorphism; FISH: Fluorescence In-Situ Hybridization; HMM: Hidden Markov Model; CEG: Conserved Eukaryotic Gene; SINE: Short 
Interspersed Nuclear Element; LINE: Long Interspersed Nuclear Element; LTR: Long Terminal Repeat; RWA: Russian wheat aphid; EST: Expressed sequence tag; NCBI: National Center for Biotechnology Information; Apis: Acyrthosiphon pisum; Dnox: Diuraphis noxia; Isca: Ixodes scapularis; Bmor: Bombyx mori; Phum: Pediculus humanus; Amel: Apis mellifera; Dmel: Drosophila melanogaster; Agam: Anopheles gambiae; OG: Ortholog group; LSE: Lineage-specific expansion; ABCt: ABC transporter; CYP450: Cytochrome P450; GST: Glutathione-S tranferase; CCE: Carboxy/ Choline esterase; GR: Gustatory receptor; OR: Odorant receptor; OBP: Odorant binding protein; GABA: Gamma-aminobutyric acid.

\section{Competing interests}

The authors declare no conflicts of interest or competing interests. Mention of trade names or commercial products in this article is solely for the purpose of providing specific information and does not imply recommendation or endorsement by the United States Department of Agriculture. USDA is an equal opportunity provider and employer.

\section{Authors' contributions}

SJN and GJP conceived of the study and prepared the genomic DNA and RNA. MN and MD sequenced the paired-end and $2.5 \mathrm{~kb}$ mated-pair libraries. $\mathrm{CK}$ and HR sequenced the $8 \mathrm{~kb}$ mated pair library and performed the genome and transcriptome assemblies. SJN, PRH, and YS completed the analyses of the genomic data. All authors read and approved the final manuscript.

\section{Acknowledgements}

We thank Dr. Dana Brunson and Jesse Schafer of the Oklahoma State University High-Performance Computing Center for providing computing hardware and technical expertise.

\section{Author details}

${ }^{1}$ USDA Agricultural Research Service, Stillwater, OK 74075, USA. ${ }^{2}$ National Institutes of Health, National Cancer Institute, Bethesda, MD 20892, USA. ${ }^{3}$ Department of Molecular Biology and Biochemistry, Oklahoma State University, Stillwater, OK 74078, USA. ${ }^{4}$ Axeq Technologies, Rockville, MD 20850, USA.

\section{Received: 8 April 2015 Accepted: 11 April 2015}

\section{Published online: 05 June 2015}

\section{References}

1. Von Dolhen CD, Moran NA. Molecular data support a rapid radiation of aphid in the Cretaceous and multiple origins of host alteration. Biol J Linnean Soc. 2000;71:689-717.

2. Misof B, Liu S, Meusemann K, Peters RS, Donath A, Mayer C, et al. Phylogenomics resolves the timing and pattern of insect evolution. Science. 2014;346:763-7.

3. Miles PW. Aphid saliva. Biol Rev. 1999;74:41-85.

4. Will T, van Bel AJ. Induction as well as suppression: How aphid saliva may exert opposite effects on plant defense. Plant Signal Behavior. 2008:3:427-30

5. Blackman RL, Eastop VF. Aphids on the world's crops: an identification and information guide. Chichester: Wiley; 2000

6. Kovalev OV, Poprawski TJ, Stekolshchikov AV, Vereshchagina AB, Gandrabur SA. Diuraphis Aizenburg (Hom., Aphididae): key to apterous viviparous females, and review of Russian language literature on the natural history of Diuraphis noxia (Kurdjumov. 1913). J Appl Entomol. 1991;112:425-36.

7. Halbert SE, Stoetzel MB. Historical overview of the Russian wheat aphid (Homoptera: Aphididae). In: Quisenberry SS, Peairs FB, editors. A response model for an introduced pest - the Russian wheat aphid (Homoptera: Aphididae). Lanham, MD: Thomas Say Publications in Entomology; 1998. p. 1-11.

8. Zhang B, Edwards O, Kang L, Fuller S. A multi-genome analysis approach enables tracking of the invasion of a single Russian wheat aphid (Diuraphis noxia) clone throughout the New World. Mol Ecol. 2014;23:1940-51.

9. Morrison WP, Peairs FB. Response model concept and economic impact. In: Quisenberry SS, Peairs FB, editors. A response model for an introduced pest - the Russian wheat aphid (Homoptera: Aphididae). Lanham, MD: Thomas Say Publications in Entomology; 1998. p. 1-11.

10. International Aphid Genomics Consortium. Genome sequence of the pea aphid, Acythrosiphon pisum. PLoS Biol. 2010;8:e1000313.
11. Novakova E, Hypša V, Klein J, Foottit RG, von Dohlen CD, Moran NA. Reconstructing the phylogeny of aphids (Hemiptera: Aphididae) using DNA of the obligate symbiont Buchnera aphidicola. Mol Phylogenet Evol. 2013;68:42-54

12. Tjallingii WF. Salivary secretions by aphids interacting with proteins of phloem wound responses. J Exp Bot. 2006;57:739-45.

13. Will T, van Bel AJ. Physical and chemical interactions between aphids and plants. J Exp Bot. 2006;57:729-37.

14. Burd JD, Burton RL. Characterization of plant damage caused by Russian wheat aphid (Homoptera: Aphididae). J Econ Entomol. 1992;85:2017-22.

15. Tamborindeguy C, Monsion B, Brault V, Hunnicutt L, Ju HJ, Nakabachi A, et al. A genomic analysis of transcytosis in the pea aphid, Acyrthosiphon pisum, a mechanism involved in virus transmission. Insect Mol Biol. 2010;19:259-72.

16. Hawthorne DJ, Via S. Genetic linkage of ecological specialization and reproductive isolation in pea aphids. Nature. 2001;412:904-7.

17. Ferrari J, Godfray HC, Faulconbridge AS, Prior K, Via S. Population differentiation and genetic variation in host choice among pea aphids from eight host plant genera. Evolution. 2006;60:1574-84.

18. Damsteegt VD, Gildow FE, Hewings AD, Carroll TW. A clone of the Russian wheat aphid (Diuraphis noxia) as a vector of the barley yellow dwarf, barley stripe mosaic, and brome mosaic viruses. Plant Dis. 1992;76:1155-60.

19. Pike KS, Allison D, Tanigoshi LK, Harwood RF, Clement SL, Halbert SE, Smith CM, Johnson JB, Reed GL, Zwer PK: Russian wheat aphid-biology, damage and management. Pacific Northwest Extension Publication. 1991, Publ. PNW371:1-23.

20. Haley SD, Peairs FB, Walker CB, Rudolph JB, Randolph TL. Occurrence of a new Russian wheat aphid biotype in Colorado. Crop Sci. 2004;44:1589-92.

21. Weiland AA, Peairs FB, Randolph TL, Rudolph JB, Haley SD, Puterka GJ. Biotypic diversity in Colorado Russian wheat aphid (Hemiptera: Aphididae) populations. J Econ Entomol. 2008;101:569-74.

22. Randolph TL, Peairs FB, Weiland A, Rudolph JB, Puterka GJ. Plant responses to seven Russian wheat aphid biotypes (Hemiptera: Aphididae) biotypes found in the United States. J Econ Entomol. 2009;102:1954-9.

23. Thompson JN, Burdon JJ. Gene-for-gene coevolution between plants and parasites. Nature. 1992;360:121-5.

24. Puterka GJ, Hammon RW, Burd JD, Peairs FB, Randolph TL, Cooper WR. Cyclical parthenogenetic reproduction in the Russian wheat aphid (Hemiptera: Aphididae) in the United States: sexual reproduction and its outcome on biotypic diversity. J Econ Entomol. 2012;105:1057-68.

25. Smith CM, Chuang W-P. Plant resistance to aphid feeding: behavioral, physiological, genetic an molecular cues regulate aphid host selection and feeding. Pest Manag Sci. 2013;70:528-40.

26. Blackman RL. Chromosome numbers in the Aphididae and their taxonomic significance. Syst Entomol. 1980;5(1):7-25.

27. Novotná J, Havelka J, Starý P, Koutecký P, Vítková M. Karyotype analysis of the Russian wheat aphid, Diuraphis noxia (Kurdjumov) (Hemiptera: Aphididae) reveals a large $X$ chromosome with rRNA and histone gene families. Genetica. 2011;39:281-9.

28. The Honeybee Genome Sequencing Consortium. Insights into social insects from the genome of the honeybee Apis mellifera. Nature. 2006;443:931-49.

29. Bosco G, Campbell P, Leiva-Neto JT, Markow TA. Analysis of Drosophila species genome size and satellite DNA content reveals significant differences among strains as well as between species. Genetics. 2007;177:1277-90.

30. Wang $X$, Fang $X$, Yang $P$, Jiang $X$, Jiang F, Zhao $D$, et al. The locust genome provides insight into swarm formation and long-distance flight. Nat Commun. 2014:5:2957.

31. Kelley JL, Peyton JT, Fiston-Lavier AS, Teets NM, Yee MC, Johnston JS, et al. Compact genome of the Antarctic midge is likely an adaptation to an extreme environment. Nat Commun. 2014;5:4611.

32. Figueroa CC, Simon J-C, Le Gallic J-F, Prunier-Leterme N, Briones LM, Dedryver C-A, et al. Genetic structure and clonal diversity of an introduced pest in Chile, the cereal aphid Sitobion avenae. Heredity. 2005;95:24-33.

33. The Tribolium Genome Sequencing Consortium. The genome of the model beetle and pest Tribolium castaneum. Nature. 2008;452:949-55.

34. Kirkness EF, Haas BJ, Sun W, Braig HR, Perotti MA, Clark JM, et al. Genome sequences of the human body louse and its primary endosymbiont provide insights into the permanent parasitic lifestyle. Proc Natl Acad Sci U S A. 2010;107:12168-73.

35. Mason JM, Frydrychova RC, Biessmann H. Drosophila telomeres: an exception providing new insights. Bioessays. 2008;30:25-37. 
36. Sahara K, Marec F, Traut W. TTAGG telomeric repeats in chromosomes of some insects and other arthropods. Chromosome Res. 1999;7:449-60.

37. Parra G, Bradnam K, Korf I. CEGMA: a pipeline to accurately annotate core genes in eukaryotic genomes. Bioinformatics. 2007;23:1061-7.

38. Glastad KM, Hunt BG, Yi SV, Goodisman MAD. DNA methylation in insects: on the brink of the epigenomic era. Insect Mol Biol. 2011;20:553-65.

39. Glastad KM, Hunt BG, Goodisman MAD. Evolutionary insights into DNA methylation in insects. Current Opinion Insect Science. 2014;1:25-30.

40. Boffelli D, Takayama S, Martin DI. Now you see it: Genome methylation makes a comeback in Drosophila. Bioessays. 2014;36:1138-44.

41. Srinivasan DG, Brisson JA. Aphids: a model for polyphenism and epigenetics. Genet Research International. 2012;2012:431531.

42. Walsh TK, Brisson JA, Robertson HM, Gordon K, Jaubert-Possamai S, Tagu D, et al. A functional DNA methylation system in the pea aphid, Acyrthosiphon pisum. Insect Mol Biol. 2010;19:215-28.

43. Elango N, Hunt BG, Goodisman MA, Yi SV. DNA methylation is widespread and associated with differential gene expression in castes of the honeybee, Apis mellifera. Proc Natl Acad Sci U S A. 2009;106:11206-11.

44. Suzuki MM, Kerr AR, De Sousa D, Bird A. CpG methylation is targeted to transcription units in an invertebrate genome. Genome Res. 2007;17:625-31.

45. Hunt BG, Brisson JA, Yi SV, Goodisman MA. Functional conservation of DNA methylation in the pea aphid and the honeybee. Genome Biol Evol. 2010;2:719-28.

46. Soria-Carrasco V, Gompert Z, Comeault AA, Farkas TE, Parchman TL, Johnston JS, et al. Stick insect genomes reveal natural selection's role in parallel speciation. Science. 2014;344:738-42.

47. Nouhaud P, Peccoud J, Mahéo F, Mieuzet L, Jaquiéry J, Simon JC. Genomic regions repeatedly involved in divergence among plant-specialized pea aphid biotypes. J Evol Biol. 2014;27:2013-20.

48. Smadja CM, Canbäck B, Vitalis R, Gautier M, Ferrari J, Zhou JJ, et al. Large-scale candidate gene scan reveals the role of chemoreceptor genes in host plant specialization and speciation in the pea aphid. Evolution. 2012;66:2723-38.

49. Ibarra-Laclette E, Lyons E, Hernández-Guzmán G, Pérez-Torres CA, Carretero-Paulet L, Chang TH, et al. Architecture and evolution of a minute plant genome. Nature. 2013;498:94-8.

50. Osanai-Futahashi M, Suetsugu Y, Mita K, Fujiwara H. Genome-wide screening and characterization of transposable elements and their distribution analysis in the silkworm, Bombyx mori. Insect Biochem Mol Biol. 2008;38:1046-57.

51. Elsik CG, Worley KC, Bennett AK, Beye M, Camara F, Childers CP, et al. Finding the missing honey bee genes: lessons learned from a genome upgrade. BMC Genomics. 2014;15:86.

52. Kaminker JS, Bergman CM, Kronmiller B, Carlson J, Svirskas R, Patel S, et al. The transposable elements of the Drosophila melanogaster euchromatin: a genomics perspective. Genome Biol. 2002;3:Research0084.1-0084.20.

53. Keeling Cl, Yuen MM, Liao NY, Docking TR, Chan SK, Taylor GA, et al. Draft genome of the mountain pine beetle, Dendroctonus ponderosae Hopkins, a major forest pest. Genome Biol. 2013;14:R27.

54. Nene V, Wortman JR, Lawson D, Haas B, Kodira C, Tu ZJ, et al. Genome sequence of Aedes aegypti, a major arbovirus vector. Science. 2007;316:1718-23.

55. You M, Yue Z, He W, Yang X, Yang G, Xie M, et al. A heterozygous moth genome provides insights into herbivory and detoxification. Nat Genet. 2013:45:220-5.

56. Holt RA, Subramanian GM, Halpern A, Sutton GG, Charlab R, Nusskern DR, et al. The genome sequence of the Malaria Mosquito Anopheles gambiae. Science. 2002;298:129-49.

57. Ratcliffe RH, Cambron SE, Flanders KL, Bosque-Perez NA, Clement SL, Ohm HW. Biotype composition of Hessian fly (Diptera: Cecidomyiidae) populations from the southeastern, midwestern, and northwestern United States and virulence to resistance genes in wheat. J Econ Entomol. 2000;93:1319-28.

58. Zhu L, Liu X, Liu X, Jeannotte R, Reese JC, Harris M, et al. Hessian fly (Mayetiola destructor) attack causes a dramatic shift in carbon and nitrogen metabolism in wheat. Mol Plant Microbe Interact. 2008;21:70-8.

59. Adams MD, Celniker SE, Holt RA, Evans CA, Gocayne JD, Amanatides PG, et al. The genome sequence of Drosophila melanogaster. Science. 2000;287:2185-95

60. Mita K, Kasahara M, Sasaki S, Nagayasu Y, Yamada T, Kanamori H, et al. The Genome Sequence of Silkworm, Bombyx mori. DNA Res. 2004;11:27-35.

61. Hill CA, Wikel SK. The Ixodes scapularis Genome Project: an opportunity for advancing tick research. Trends Parasitol. 2005;21:151-3.
62. Smadja C, Shi P, Butlin RK, Robertson HM. Large gene family expansions and adaptive evolution for odorant and gustatory receptors in the pea aphid, Acyrthosiphon pisum. Mol Biol Evol. 2009;26:2073-86.

63. Duvaux L, Geissmann Q, Gharbi K, Zhou JJ, Ferrari J, Smadja CM, et al. Dynamics of copy number variation in host races of the pea aphid. Mol Biol Evol. 2015;32:63-80.

64. De Vos M, Jander G. Myzus persicae (green peach aphid) salivary components induce defence responses in Arabidopsis thaliana. Plant Cell Environ. 2009;32:1548-60

65. Kehr J. Phloem sap proteins: their identities and potential roles in the interaction between plants andphloem-feeding insects. J Exp Bot. 2006;57:767-74.

66. Carolan JC, Fitzroy Cl, Ashton PD, Douglas AE, Wilkinson TL. The secreted salivary proteome of the pea aphid Acyrthosiphon pisum characterised by mass spectrometry. Proteomics. 2009;9:2457-67.

67. Walling LL. The myriad plant responses to herbivores. J Plant Growth Regul. 2000;19:195-216.

68. Boyko EV, Smith CM, Thara VK, Bruno JM, Deng Y, Starkey SR, et al. Molecular basis of plant gene expression during aphid invasion: wheat Pto- and Pti-like sequences are involved in interactions between wheat and Russian wheat aphid (Homoptera: Aphididae). J Econ Entomol. 2006;99:1430-45

69. Nicholson SJ, Hartson SD, Puterka GJ. Proteomic analysis of secreted saliva from Russian wheat aphid (Diuraphis noxia Kurd.) biotypes that differ in virulence to wheat. J Proteomics. 2012;75:2252-68.

70. Telang A, Sandstrom J, Dyreson E, Moran NA. Feeding damage by Diuraphis noxia results in a nutritionally enhanced phloem diet. Ent Exp App. 1999;91:403-12.

71. Sandström J, Telang A, Moran NA. Nutritional enhancement of host plants by aphids - a comparison of three aphid species on grasses. J Insect Physiology. 2000;46:33-40.

72. Cooper RW, Dillwith JW, Puterka GJ. Comparisons of salivary proteins from five aphid (Hemiptera: Aphididae) species. Environ Entomol. 2011;40:151-6.

73. Nicholson SJ, Puterka GJ. Variation in the salivary proteomes of differentially virulent greenbug (Schizaphis graminum Rondani) biotypes. J Proteomics. 2014;105:186-203.

74. Rao SA, Carolan JC, Wilkinson TL. Proteomic profiling of cereal aphid saliva reveals both ubiquitous and adaptive secreted proteins. PLoS One. 2013;8:e57413

75. Pineda SS, Melgar S, Dorn PL, Agreda E, Rodas A, Monroy C. Salivary protein profiles distinguish triatomine species and populations of Triatoma dimidiata (Hemiptera: Reduviidae). J Med Entomol. 2008;45:2-8.

76. Vandermoten S, Harmel N, Mazzucchelli G, De Pauw E, Haubruge E, Francis F. Comparative analyses of salivary proteins from three aphid species. Insect Mol Biol. 2014;23:67-77.

77. Ramsey JS, Rider DS, Walsh TK, De Vos M, Gordon KH, Ponnala L, et al. Comparative analysis of detoxification enzymes in Acyrthosiphon pisum and Myzus persicae. Insect Mol Biol. 2010;19:155-64.

78. Zhang B, Ma C, Edwards O, Fuller S, Kang L. The mitochondrial genome of the Russian wheat aphid Diuraphis noxia: large repetitive sequences between trnE and trnF in aphids. Gene. 2014:533:253-60.

79. Matsuo T, Sugaya S, Yasukawa J, Aigaki T, Fuyama Y. Odorant-binding proteins OBP57d and OBP57e affect taste perception and host-plant preference in Drosophila sechellia. PLoS Biol. 2007:5:e118.

80. Cao D, Liu Y, Walker WB, Li J, Wang G. Molecular characterization of the Aphis gossypii olfactory receptor gene familes. PLoS One. 2014;9:e101187.

81. Scott JG, Warren WC, Beukeboom LW, Bopp D, Clark AG, Giers SD, et al. Genome of the house fly, Musca domestica L., a global vector of diseases with adaptations to a septic environment. Genome Biol. 2014;15:466.

82. Huvenne H, Smagghe G. Mechanisms of dsRNA uptake in insects and potential of RNAi for pest control: a review. J Insect Physiology. 2010;56:227-35

83. Milon BC, Cheng H, Tselebrovsky MV, Lavrov SA, Nenasheva W, Mikhaleva $E A$, et al. Role of histone deacetylases in gene regulation at nuclear lamina. PLoS One. 2012;7:e49692.

84. Bansal R, Michel AP. Core RNAi machinery and sid1, a component for systemic RNAi, in the hemipteran insect. Aphis glycines. Int J Mol Sci. 2013;14:3786-801.

85. Bayoun IM, Plapp FW, Gilstrap FE, Michels GJ. Toxicity of selected insecticides to Diuraphis noxia (Homoptera:Aphididae) and its natural enemies. J Econ Entomol. 1995;88:1177-85. 
86. Michaud JP, Whitworth RJ, Davis HN. Wheat Insect Management 2014 Department of Entomology, Kansas State University. March 2014.

87. Field LM, Blackman RL, Tyler-Smith C, Devonshire AL. Relationship between amount of esterase and gene copy number in insecticide-resistant Myzus persicae (Sulzer). Biochem J. 1999;339:737-42.

88. Bass C, Puinean AM, Zimmer CT, Denholm I, Field LM, Foster SP, et al. The evolution of insecticide resistance in the peach potato aphid, Myzus persicae. Insect Biochem Mol Biol. 2014:51:41-51.

89. Shang Q, Pan Y, Fang K, Xi J, Wong A, Brennan JA, et al. Extensive Ace2 duplication and multiple mutations on Acel and Ace2 are related with high level of organophosphates resistance in Aphis gossypii. Environ Toxicol. 2012;29:526-33.

90. Bass C, Puinean AM, Andrews MC, Culter P, Daniels M, Elias J, et al. Mutation of a nicotinic acetylcholine receptor $\beta$ subunit is associated with resistance to neonicitinoid insecticides in the aphid Myzus persicae. BMC Neurosci. 2011;12:51.

91. Valenzuela I and Hoffman AA. Effects of aphid feeding and associated virus injury on grain crops in Australia. Austral Entomology 2014, in Press.

92. Baumann L, Baumann P, Moran NA. The endosymbiont (Buchnera) of the aphid Diuraphis noxia contains all the genes of the tryptophan biosynthetic pathway. Curr Microbiol. 1998;37:58-69.

93. Swanevelder ZH, Surridge AK, Venter E, Botha AM. Limited endosymbiont variation in Diuraphis noxia (Hemiptera: Aphididae) biotypes from the United States and South Africa. J Econ Entomol. 2010;103:887-97.

94. Oliver KM, Degnan PH, Burke GR, Moran NA. Facultative symbionts in aphids and the horizontal transfer of ecologically important traits. Annu Rev Entomol. 2010;55:247-66.

95. Nikoh N, Nakabachi A. Aphids acquired symbiotic genes via lateral gene transfer. BMC Biol. 2009;7:12.

96. Becerra JX. The impact of herbivore-plant coevolution on plant community structure. Proc Natl Acad Sci U S A. 2007:104:7483-8.

97. Howe GA, Jander G. Plant immunity to insect herbivores. Annu Rev Plant Biol. 2008;59:41-66.

98. Butler J, MacCallum I, Kleber M, Shlyakhter IA, Belmonte MK, Lander ES, et al. ALLPATHS: de novo assembly of whole-genome shotgun microreads. Genome Res. 2008;18:810-20

99. Gnerre S, Maccallum I, Przybylski D, Ribeiro FJ, Burton JN, Walker BJ, et al. High-quality draft assemblies of mammalian genomes from massively parallel sequence data. Proc Natl Acad Sci U S A. 2011;108:1513-8.

100. Grabherr MG, Haas BJ, Yassour M, Levin JZ, Thompson DA, Amit I, et al. Full-length transcriptome assembly from RNA-seq data without a reference genome. Nat Biotechnol. 2011;29:644-52.

101. Smit AFA and Hubley R, Green P. RepeatMasker Open-3.0. 1996-2010 [http://www.repeatmasker.org]

102. Smit AFA and Hubley R. RepeatModeler Open-1.0. 2008-2010 [http:// www.repeatmasker.org]

103. Cantarel BL, Korf I, Robb SM, Parra G, Ross E, Moore B, et al. MAKER: an easy-to-use annotation pipeline designed for emerging model organism genomes. Genome Res. 2008;18:188-96.

104. Stanke M, Keller O, Gunduz I, Hayes A, Waack S, Morgenstern B. AUGUSTUS: $a b$ initio prediction of alternative transcripts. Nucleic Acids Res. 2006;34:W435-439.

105. Chen F, Mackey AJ, Vermunt JK, Roos DS. Assessing performance of orthology detection strategies applied to eukaryotic genomes. PLoS One. 2007;2:e383.

106. Edgar RC. MUSCLE: multiple sequence alignment with high accuracy and high throughput. Nucleic Acids Res. 2004;32:1792-7.

\section{Submit your next manuscript to BioMed Central and take full advantage of:}

- Convenient online submission

- Thorough peer review

- No space constraints or color figure charges

- Immediate publication on acceptance

- Inclusion in PubMed, CAS, Scopus and Google Scholar

- Research which is freely available for redistribution

Submit your manuscript at www.biomedcentral.com/submit 